\title{
Prevalence of dental caries based on gender, age, Black's classification and its distribution on different teeth
}

\author{
Steven Tan Jun Hong*, Mohammad Richata Fadil*, Dudi Aripin* \\ *Department of Conservative Dentistry Faculty Of Dentistry Universitas Padjadjaran
}

\begin{abstract}
Introduction: Dental caries (tooth decay) is probably the most common chronic disease in the world. Greene Vardiman Black in the end of nineteenth century presented G. V. Black's classification. The study is aimed to find out the prevalence of dental caries based on gender, age, Black's classification and its distribution on different teeth. Methods: This research is a descriptive research, conducted by collecting the data from patients' medical records from Bagian Gigi dan Mulut in RSHS, Bandung and then analyzed the collected data. Results: The result of this study shows that Class I caries is the most common type of carious lesion (37.1\%) and the mandibular molars are the most common teeth affected by caries (32.4\%). Female is more prone to caries than males $(60.5 \%)$ and the early adulthoods have the highest rate of caries occurrence $(46.1 \%)$. Conclusion: It can be concluded that Class I caries is the most common type of carious lesion based on G. V. Black's classification. Besides that, female is found to be more prone to caries than male and the early adulthoods had the highest rate of caries occurrence.
\end{abstract}

Keywords: Dental caries, gender, age, Black's classification, teeth.

\section{INTRODUCTION}

Dental caries (tooth decay) is probably the most common chronic disease in the world. Although caries has affected human since prehistoric times, the prevalence of this disease has increased greatly in modern times worldwide, an increase strongly associated with dietary change. Dental caries is defined as an infectious microbiologic disease of the teeth that results in localized dissolution and destruction of the calcified tissues. ${ }^{1}$

Incidence of caries in developing country especially in Indonesia is still considered quite high. Based on basic medical research in Indonesia, Riset Kesehatan Dasar (RISKESDAS), in the year of 2007, Index DMF-T nationally is 4.85 . This means that average tooth decay among Indonesian is 5 teeth per person. The largest component is extracted or missing teeth/ M-T which occupied 3.86. In other words, average population of Indonesian has 4 teeth been extracted or indicated for extraction. DMF-T for West Java Province is 4.03 , this means that average tooth decay among citizens in West Java is 4 teeth per person.

The largest component is extracted or missing teeth/M-T which occupied 3.71. In other words, average population of West Java has 4 teeth been extracted or indicated for extraction. Prevalence for active caries is $39.0 \%$ and caries experience is $58.4 \%{ }^{2}$ Dental caries is a multifactorial disease in which there is interplay of three primary factors: the host, the microbial 
flora and the substrate. In addition a fourth factor, the time must be considered in any discussion on the etiology of caries. In other words, caries requires a susceptible host, a cariogenic flora and a suitable substrate that must be present for a sufficient length of time. ${ }^{3}$ The prevalence of caries experience was highest among individuals between the ages of 17 and $25 .{ }^{4}$ However, root caries is more common in older patients. Root caries has become an important dental problem because people are living longer and keeping their teeth longer. ${ }^{5}$ On the other hand, women showed a higher incidence $(59.1 \%)$ of caries than males $(40.9 \%){ }^{4}$

Deciduous as well as permanent teeth show carious lesions, usually in molars. In the permanent dentition, about $25-51 \%$ of molars are carious whereas only $6-26 \%$ of other tooth types are decayed. ${ }^{6}$ Occlusal caries is the most common type of caries on the permanent teeth. Studies show that $43-75 \%$ of all caries lesions are on the occlusal surfaces of posterior teeth. In the entire dentition, there are more mesial cavities than distal; in the lower molars there are more buccal cavities than lingual cavities, while in the upper molars the ratio is reversed. The cuspal, incisal, buccal, lingual, and palatal surfaces are usually resistant to dental caries. This resistance is related to external factors such as food retention and the formation of dental plaque.

The most susceptible areas for dental caries are the fissures and proximal surfaces of the teeth. ${ }^{6}$ Greene Vardiman Black commonly known as G.V. Black is known as one of the founders of modern dentistry in the United States. G.V. Black in the end of nineteenth century, presented a simple cavity classification listed as class I, class II, class III, class IV and class V, an additional class VI was later on added by Simon as modification to Black's classification.

The high caries prevalence is due to lack of seriousness by the people and government in handling this problem. Many people still do not aware of the importance of routine check-up to the dentist before the occurrence of increase caries activity in their oral cavity. On the other side, the role of dentists as counselors when dealing with patients is still lacking. The author is interested in carrying out this minor thesis because it can provide useful information to the public about the most common type of carious lesions appear in the oral cavity. Thus, from the information, they may pay more attentions on the surfaces that easily can be infected by caries when they are cleaning their oral cavity.

\section{METHODS}

This research is a retrospective descriptive research, describing a look back at patient's medical history and characteristics from the population being studied. The population is the medical records from Bagian Gigi dan Mulut in Rumah Sakit Hasan Sadikin (RSHS), Bandung. The sample of this research is medical records from Bagian Gigi dan Mulut in Rumah Sakit Hasan Sadikin (RSHS), Bandung from 1 August 2010 to 30 September 2011. From the medical records, the information such as name, gender, age, tooth surfaces affected by caries, G.V. Black's Classification of carious lesions is taken. The results from the data collection is continued to be analyzed statistically using the computer program SPSS (Statistical Package for Social Science) version 13.

\section{RESULTS}

Research on The Most Common Type of Carious Lesions Based on Green Vardiman Black Classification based on data collected (medical records) from Rumah Sakit Hasan Sadikin Bandung. Data collected from 1 October to 30 September 2011 , there is a total amount of 167 patients, i.e. 66 male and 101 female (Table 1 ).

The patients' information is taken and recorded.

Table 1. The Number of Male and Female Patients

\begin{tabular}{cc}
\hline Gender & Number of Patient \\
\hline Male & 66 \\
Female & 101 \\
\hline Total & 167 \\
\hline
\end{tabular}

Such information is name, gender, age, tooth affected by caries, G. V. Black's classification and tooth surfaces affected by caries. G. V. Black's classification and the frequency of patients for each class is recorded into Table 2. Besides that, teeth affected by caries are recorded into Table 3 . 
Table 2. The Frequency of Patients for Each Classes of G. V. Black's Classification

\begin{tabular}{ccc}
\hline $\begin{array}{c}\text { G. V. Black's } \\
\text { Classification }\end{array}$ & Frequency & $\begin{array}{c}\text { Precent } \\
\%\end{array}$ \\
\hline I & 62 & 37.1 \\
II & 34 & 20.4 \\
III & 37 & 22.2 \\
IV & 12 & 7.2 \\
V & 22 & 13.2 \\
VI & 0 & 0 \\
\hline Total & 167 & 100 \\
\hline
\end{tabular}

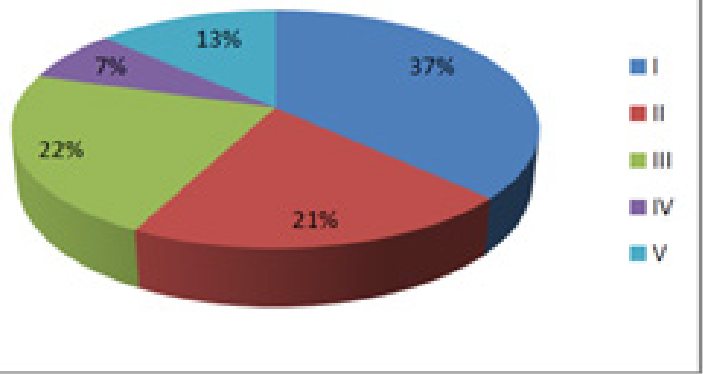

Figure 1. Pie Chart for G.V. Black’s Classification

Table 3. Teeth Affected by Caries

\begin{tabular}{|c|c|c|}
\hline Tooth & Frequency & $\begin{array}{c}\text { Precentage } \\
\%\end{array}$ \\
\hline 11 & 13 & 7.8 \\
\hline 12 & 6 & 3.6 \\
\hline 14 & 4 & 2.4 \\
\hline 15 & 3 & 1.8 \\
\hline 16 & 4 & 2.4 \\
\hline 17 & 6 & 3.6 \\
\hline 18 & 1 & 0.6 \\
\hline 21 & 14 & 8.4 \\
\hline 22 & 9 & 5.4 \\
\hline 23 & 6 & 3.6 \\
\hline 24 & 5 & 3.0 \\
\hline 25 & 3 & 1.8 \\
\hline 26 & 10 & 6.0 \\
\hline 27 & 6 & 3.6 \\
\hline 31 & 2 & 1.2 \\
\hline 32 & 2 & 1.2 \\
\hline 33 & 1 & 0.6 \\
\hline 34 & 2 & 1.2 \\
\hline 35 & 3 & 1.8 \\
\hline 36 & 5 & 3.0 \\
\hline 37 & 10 & 6.0 \\
\hline 38 & 1 & 0.6 \\
\hline
\end{tabular}

\begin{tabular}{ccc}
43 & 4 & 2.4 \\
44 & 4 & 2.4 \\
45 & 5 & 3.0 \\
46 & 21 & 12.6 \\
47 & 15 & 9.0 \\
48 & 2 & 1.2 \\
\hline Total & 167 & 100 \\
\hline
\end{tabular}

Table 4. Gender Cross Tabulation for G. V. Black's Classification

\begin{tabular}{|c|c|c|c|}
\hline $\begin{array}{l}\text { G. V. Black's } \\
\text { Classification }\end{array}$ & \multicolumn{2}{|c|}{ Gender } & Total \\
\hline & Male & Female & \\
\hline \multirow[t]{2}{*}{ I } & 24 & 38 & 62 \\
\hline & $38.7 \%$ & 61.3 & \\
\hline \multirow[t]{2}{*}{ II } & 10 & 24 & 34 \\
\hline & $29.4 \%$ & $70.6 \%$ & \\
\hline \multirow[t]{2}{*}{ III } & 17 & 20 & 37 \\
\hline & $45.9 \%$ & $54.1 \%$ & \\
\hline \multirow[t]{2}{*}{ IV } & 4 & 8 & 12 \\
\hline & $33.3 \%$ & $66.7 \%$ & \\
\hline \multirow[t]{2}{*}{ V } & 11 & 11 & 22 \\
\hline & $50.0 \%$ & $50.0 \%$ & \\
\hline \multirow[t]{2}{*}{ VI } & 0 & 0 & 0 \\
\hline & $0 \%$ & $0 \%$ & \\
\hline \multirow[t]{2}{*}{ Total } & 66 & 101 & 167 \\
\hline & $39.5 \%$ & $60.5 \%$ & $100 \%$ \\
\hline
\end{tabular}

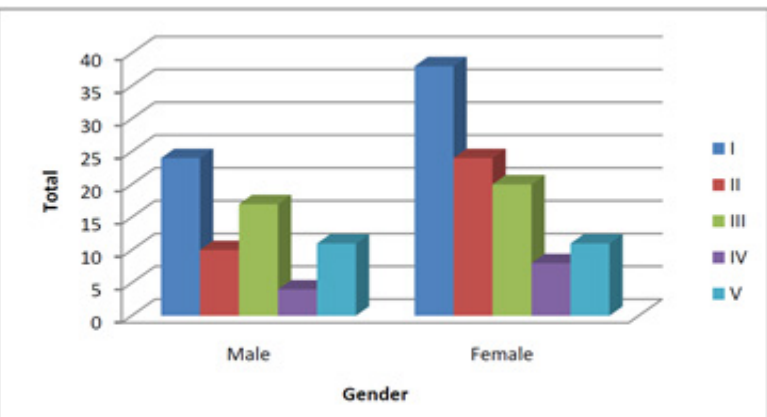

Figure 2. Graphic of G. V. Black's Classification by Gender

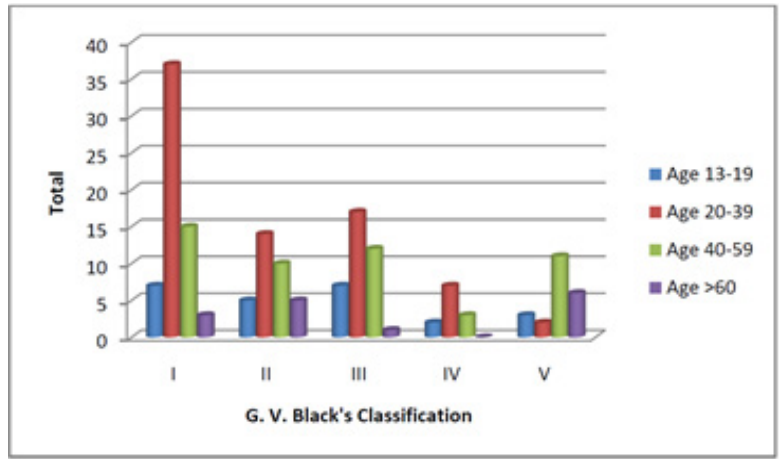

Figure 3. Graphic of G. V. Black Classification by Age 
In this research, the relationship between two variables (age and gender) and the results (tooth affected by caries and G. V. Black classification) is further explored. G.V. Black's classification of carious lesions for different gender is presented in Table 4 and Figure 2, and for different age groups is presented in Table 5 and Figure 3.

\section{DISCUSSION}

From Table 4.2, the most common caries lesions based on G.V. Black's classification is Class I (62, $37.1 \%)$, followed by Class III $(37,22.2 \%)$, Class II $(34,20.4 \%)$, Class V $(22,13.2 \%)$ and the last is the Class IV (12, 7.2\%). Conventionally, high incidence of caries on occlusal surfaces (Class I) has been directly related to the narrow and inaccessible pits and fissures. ${ }^{7}$

This is due to their mechanical characteristics which result in poor self-cleansing features. Deep narrow pits and fissures favor the retention of food debris along with microorganisms and caries may result from fermentation of this food and the formation of acid. ${ }^{3}$

For the proximal surfaces (Class II and Class III), it is particularly susceptible to caries because of the extra shelter proved to resident plaque owing to the proximal contact area immediately occlusal to the plaque.1 Caries of proximal surfaces also may relate to cases of malposed or malformed teeth, due to the self-cleansing features. Cervical caries (Class V) is found commonly in older age people. This is due to the physiological gingival recession at the older age leaves the root surface exposed to the oral environment. The root surface is rougher than enamel and readily allows plaque formation in the absence of good oral hygiene. The cementum covering the root surface is extremely thin and provides little resistance to caries attack. ${ }^{3}$

Moreover, normally the patients with Class $\checkmark$ caries like to consume sour or acidic food and drink such as 'pempek' and tamarind juice which are found commonly in Indonesia. Cuspid surface in this research includes incisal edge of the anterior teeth (Class IV) and the cusp tip regions of the posterior teeth (Class $\mathrm{VI}$ ).

However, from the data collected, there is no patient with Class VI caries. Normally, Class IV is caused by attrition (loss of tooth substance from the occluding of food, abrasives and opposing teeth) and fracture of the enamel which remove the enamel to expose the underlying dentin on those areas. Such a wear pattern occurs more often in geriatric patients. ${ }^{1}$

In this research, mandibular molars were apparently most susceptible to caries and the mandibular incisors and canines were least susceptible to caries. The mandible right first molars had the frequency of 21 patients with the highest percentage of $12.6 \%$ (Table 3 ). The reason for this phenomenon could be a combination of complicated surface morphology and difficult access for effective oral hygiene.

Deep pits and fissures and broadest contact points of molars cause them be more susceptible to caries compared to the other type of teeth. Moreover, mandible first molar is one of the earliest (6-7 years old) to erupt in the permanent dentition. Soon after an eruption, a majority of fissures of occlusal surfaces of molars show early signs of caries. In the other hand, mandible incisors and canines were the least caries occurrence could be due to the cleansing action of tongue is more at the lower anterior teeth and this area is near to the sublingual salivary gland, this means that the buffering action of saliva in this area is strong. ${ }^{4}$

The present research showed that females have more caries than males; the percentages are $60.5 \%$ and $39.5 \%$ respectively (Table 4 ). In general, permanent teeth erupt earlier in females than in males. As they are exposed to the risk of caries for longer period, it is logical to assume that females' teeth would decay more than the teeth of their males counterparts of the same age. ${ }^{4}$

The composition and flow rate of saliva in the host oral environment seem to be another source of susceptibility of caries formation in women. Saliva plays a protective role in the oral cavity through its buffering, mechanical washing, antimicrobial, and remineralization activities. ${ }^{8}$

However, the flow rates of saliva and compositional analysis have been shown to be generally less protective in women than in men. Women during pregnancy have negatives effects on immune system (immune suppression) and salivary flow. ${ }^{9}$ Women have food cravings, variations in immune response, and aversions during pregnancy. Women have an aversion to 
meat in the first trimester and crave high-energy, sweet foods during the third trimester. Female sex hormones and associated physiological factors can significantly affect cavity formation. Evidence from animal models suggests that female estrogens, but not male androgens, correlate with caries rates. It is possible that there is a cumulative effect of estrogens, including fluctuations at puberty and high levels during pregnancy, which promotes caries. $^{8}$

In Table 4.5, the 167 patients are divided into four age groups, juvenile (13-19 years old), early adulthood (20-39 years old), middle adulthood (40-59 years old) and late adulthood $(60>)$. This research showed that the patients in early adulthood group had the highest rate of caries occurrence for all classes of G.V. Black's classification except for Class $V$ or known as 'root caries'. The high caries prevalence could be due to the diet habits of the early adulthood people. This group of people possibly likes to snack between meals on cariogenic sweet food or high sucrose contained food. ${ }^{10}$

Patients in middle adulthood and late adulthood had the highest prevalence of caries on Class $\mathrm{V}$ caries. As patients grow older, their gums recede and root surfaces are exposed, making them more susceptible to root caries. Any caries-prone patient having gingival recession can develop root caries.

However, the elderly are usually more vulnerable to root caries because of several medical conditions. Many older patients use medications that reduce saliva flow and cause them to have a dry mouth. Besides that, several elderly have the physical difficulties to brush teeth or clean the oral cavity leading to poor oral health conditions. ${ }^{11}$

\section{CONCLUSION}

Based on the study conducted, it can be concluded that Class I caries is the most common type of carious lesions. Mandibular molars are most commonly affected by caries. Besides that, females are more prone to caries attack than males. This study also concludes that people in early adulthood (20-39) age group has the highest rate of caries incidence.

\section{REFERENCES}

1. Roberson TM, Studervant's Art and Science of Operative Dentistry. 5th edition. India: Elsevier. 2009. p. 65-131.

2. Aripin D. Hubungan kadar sCD14, Jumlah Streptococcus Mutans, pH-Buffer, Fluor di dalam Saliva dengan Kejadian Karies pada Anak Karyawan PTPN VIII Pangalengan Usia 12-15 Tahun (suatu Upaya Penelusuran Pathogenitas). Bandung: Universitas Padjadjaran. 2011.

3. Rajendran R, Sivapathasundharam B. Shafer's Textbook of Oral Pathology. $6^{\text {th }}$ edition. India: Elsevier. 2009. p. 409-473

4. Demirci M. Prevalence of caries on individual tooth surfaces and its distribution by age and gender in university clinic patients. USA: Europ J Dent. 2010.

5. Gupta B. Root caries: an ageing problem. USA: Internet Scientific Publications. 2007.

6. Lanfranco LP. Eggers S. The usefulness of caries frequency, depth, and location in determining cariogenicity and past subsistence: a test on early and later agriculturalists from the peruvian coast. 2010.

7. Fejerskov O, Kidd EAM. Dental Caries The Disease and Its Clinical Management. Minion: Blackwell Munksgaard. 2003

8. Jindal Al. Women are more susceptible to caries but individuals born with clefts are not. USA: International Journal of Dentistry. 2011

9. ira AR. Explaining gender differences in caries: a multifactorial approach to a multifactorial disease. USA: International Journal of Dentistry. 2010.

10. Fujita H. Age- and sex- related dental caries prevalence in Japanese from the Jomon period. 2007.

11. Gupta, B., et al. 2007. Root caries: an ageing problem. USA: Internet Scientific Publications. Available online at http://www.ispub.com/ journal / the-internet-journal-of-dentalscience/volume-5-number-1/root-caries-anaging-problem.html 